\title{
ASEPTIC MENINGITIS CAUSED BY ECHO VIRUS
}

\author{
BY O. LAHELLE \\ Kaptein W. Wilhelmsen og Frues Bakteriologiske Institutt, \\ Oslo University, Oslo, Norway
}

\section{INTRODUCTION}

Viruses unrelated antigenically to the poliomyelitis, Coxsackie or adeno-viruses have, not infrequently, been isolated from the faeces of patients diagnosed as suffering from non-paralytic poliomyelitis or aseptic meningitis. Similar viruses have been recovered from the stools of apparently normal children. Robbins, Enders, Weller \& Florentino (1951) isolated by tissue culture methods a cytopathogenic agent which could not be identified with any known virus, and similar agents have been reported by other investigators. This group of viruses has now been labelled Enteric Cytopathogenic Human Orphan (ECHO) viruses and falls into at least fourteen distinct antigenic types (Riordan, Ledinko \& Melnick, 1952; Du ncan Silverthorne, McNaughton, Johnsson \& Rhodes, 1954; Melnick, 1954; Committee on the ECHO viruses, 1955; Davis \& Melnick, 1956). In the 'Summary Report on Evaluation of the Field Trial of Poliomyelitis Vaccine' (1955) there is reference to the isolation of ECHO viruses, mostly from cases diagnosed as non-paralytic poliomyelitis. The significance of these viruses as aetiological agents of clinical disease was not determined. From normal children the isolation of viruses belonging to this group has been reported by Ramos-Alvarez \& Sabin (1954) and Honig, Melnick, Isacson, Parr, Myers \& Walton (1956).

The association of certain antigenic types of these viruses with disease in man had, however, been suspected and recent reports indicate a relationship between ECHO virus, Type 6, and aseptic meningitis. Svedmyr, Melén \& Kjellén (1956) encountered a significantly greater number of strains of this Type in patients with aseptic meningitis than in a control group. Davis \& Melnick (1956) also isolated several strains of Type 6 from cases of aseptic meningitis and, moreover, they were able to demonstrate specific antibody rises in the paired sera of such patients.

This work is concerned with the relationship of ECHO virus Type 6 to disease of man; it will be shown that in cases of aseptic meningitis the virus can be isolated not only from the patient's stool but also from the cerebrospinal fluid and the throat-washing. Furthermore, there is a rise in antibody during the course of the disease. A preliminary report on the findings has appeared recently (Lahelle, 1957a). In addition, clinical and epidemiological observations on what is considered to be ECHO virus infections are reported.

\section{MATERIALS AND METHODS}

The procedures for isolation of poliomyelitis and $\mathrm{ECHO}$ viruses have been described in detail elsewhere (Lahelle, 1954, 1956, 1957b), but a brief outline of the methods are given below. 


\section{Tissue cultures}

Primary explant cultures of human embryonic tissue. Pieces of skin-muscle tissue mixed with chicken plasma and chick embryo extract were spread on the inner surface of glass tubes. When coagulation was complete $1 \mathrm{ml}$. of fluid nutrient medium was introduced into each tube. Bovine amniotic fluid with $5 \%$ horse serum served as nutrient medium during the outgrowth of cells, and bovine amniotic fluid with $2 \%$ calf serum was employed as nutrient medium in the virus-inoculated culture tubes. Incubation took place in a roller drum at $36^{\circ} \mathrm{C}$.

Human amnion cultures. Human amniotic cells were obtained by trypsinization of amniotic membranes at $30^{\circ} \mathrm{C}$. for $3 \mathrm{hr}$. Approximately $0 \cdot 2-0.3 \times 10^{6}$ cells in $1 \mathrm{ml}$. fluid medium were introduced into each tube, and primary incubation took place in a stationary position for $2-3$ days followed by change of fluid nutrient medium and incubation in a roller drum for 2-4 days. Here bovine amniotic fluid with $10 \%$ human serum and $5 \%$ placental extract was used as nutrient medium during the period of outgrowth of cells, while bovine amniotic fluid with $2 \%$ calf serum served as fluid medium in the virus-inoculated culture tubes. The cultures were washed twice with saline before inoculation of the virus-containing material.

\section{Isolation of virus}

Faecal material was ground in a mortar with distilled water to make a $20 \%$ suspension which was centrifuged at 3000 r.p.m. for $30 \mathrm{~min}$. Penicillin and streptomycin were added to the supernate to give a concentration of 1000 units and $250 \mu \mathrm{g}$. respectively. Six culture tubes were used for each faecal specimen; two tubes received $0.1 \mathrm{ml}$., two tubes $0.2 \mathrm{ml}$., and the remaining two, $0.5 \mathrm{ml}$. of the faecal suspension.

Cerebrospinal fluid was inoculated into the culture tubes in $0.5 \mathrm{ml}$. amounts. Three or four tubes were used for each specimen.

Throat washings were treated with penicillin and streptomycin first and then introduced in amounts of $0.5 \mathrm{ml}$. into each of three or four culture tubes.

All cultures were incubated at $36^{\circ} \mathrm{C}$. in a roller-drum for about $3 \mathrm{hr}$. after which the fluid culture medium was changed. Each tube was examined daily for evidence of cytopathogenic changes attributable to virus activity and as soon as any change was observed or suspected the fluid was harvested and passed to fresh cultures. Tubes failing to show any cellular changes were discarded after 10-20 days.

\section{Typing of virus strains}

Anti-sera against the poliomyelitis and ECHO viruses were prepared in rabbits. The animals were immunized by the intraperitoneal inoculation of $15 \mathrm{ml}$. of viruscontaining tissue, culture fluid on each of 3 consecutive days, and were bled on the 4th day after the last injection. The tissue culture fluids used as inocula for the rabbits contained not less than $10^{7} \mathrm{ID}_{50}$ of virus per ml. Some rabbit sera showed a slight or moderate degree of non-specific neutralizing capacity and were discarded; normal rabbit sera frequently exhibited non-specific neutralization. Poliomyelitis reference sera were kindly supplied by Dr H. A. Wenner, Kansas; 
U.S.A., and the specific Type 6 ECHO serum was tested and found satisfactory at the State Bacteriological Laboratory, Stockholm, Sweden. The typing was carried out according to methods previously described (Lahelle, 1954) except for the fact that the serum-virus mixtures were held at $37^{\circ} \mathrm{C}$. for $1 \mathrm{hr}$. before inoculation of amnion cell cultures.

\section{Serological tests}

Neutralizing antibodies against poliomyelitis and ECHO viruses were determined on paired sera heated at $56^{\circ} \mathrm{C}$. for $\frac{1}{2} \mathrm{hr}$. The titrations were carried out using fourfold dilutions of serum against about $100 \mathrm{ID}_{50}$ of virus in $0.1 \mathrm{ml}$. saline. The serumvirus mixtures were incubated in a water bath at $37^{\circ} \mathrm{C}$. for $1 \mathrm{hr}$. For each serum dilution $0 \cdot 1 \mathrm{ml}$. of serum-virus mixture was inoculated into each of two amnion cell culture-tubes, which were then incubated in a roller drum at $36^{\circ} \mathrm{C}$. for 4 days. The end-point was taken as the highest final dilution of serum which prevented cytopathogenic changes in $50 \%$ of the culture tubes. The $50 \%$ end-point was calculated.

\section{RESULTS}

\section{Virus isolations}

In the autumn of 1955 faecal specimens from 135 patients with a diagnosis of either paralytic poliomyelitis or aseptic meningitis were examined for the presence of virus. All the specimens were collected within 2 weeks of onset, and by far the most were obtained within the first week of the illness. Only one sample was collected from each patient in this series. In addition faecal specimens from eighteen patients with a diagnosis other than poliomyelitis or aseptic meningitis were also examined for the presence of a cytopathogenic virus.

Attempts were also made to isolate cytopathogenic viruses from forty-one cerebrospinal fluids and twenty-four throat-washings from the same two groups of patients.

The faecal suspensions were inoculated into either fibroblastic or into amnion cell cultures, or into both types of tissue-culture media. The cerebrospinal fluids and throat washings were all tested in amnion cell cultures. Experience in this laboratory indicated that amnion-cell cultures were more effective than fibroblastcell cultures for the isolation of viruses of poliomyelitis and ECHO Type 6 (Lahelle $1957 b)$.

The results of the isolation experiments are shown in Table 1 and may be summarized as follows: Poliomyelitis virus was isolated from twenty-two out of thirtyseven stools from cases of paralytic poliomyelitis and from none of these was an ECHO virus recovered. On the other hand, while there were forty-eight isolations of ECHO virus Type 6 from ninety-eight cases of aseptic meningitis (non-paralytic poliomyelitis) only twelve strains of the poliomyelitis viruses were recovered. Many faecal suspensions from patients suffering from an aseptic meningitis were inoculated into baby mice without effect and several ECHO virus strains, after two or three passages through tissue culture, were also tested in sucklings with negative results. 
ECHO virus Type 6 was isolated from two patients whose illness did not fit the clinical picture of paralytic poliomyelitis or aseptic meningitis. It is possible, however, that they were subclinical cases of aseptic meningitis.

Table 1. Isolation of poliomyelitis and ECHO viruses from 153 individuals hospitalized in the fall of 1955

$\begin{array}{lcccccc}\text { Specimen } & \begin{array}{c}\text { No. } \\ \text { tested }\end{array} & \begin{array}{c}\text { No. } \\ \text { positive }\end{array} & \text { P1 } & \text { P2 } & \text { P3 } & \text { E }\end{array}$

Freces

Cerebrospinal fluid

Throat-washing

Paralytic poliomyelitis

$\begin{array}{lll}37 & 22 & 13\end{array}$

\begin{tabular}{|c|c|c|c|c|}
\hline \multicolumn{5}{|c|}{ Aseptic meningitis } \\
\hline 60 & 6 & 1 & 5 & 48 \\
\hline 6 & 0 & 0 & 0 & $6^{*}$ \\
\hline 4 & 0 & 0 & 0 & $4^{* *}$ \\
\hline
\end{tabular}

\section{Faeces \\ Cerebrospinal fluid \\ Throat-washing}

Faeces
Cerebrospinal fluid
Throat-washing

\section{Other diseases}

$\begin{array}{rlllll}18 & 2 & 0 & 0 & 0 & 2 \\ 10 & 0 & 0 & 0 & 0 & 0 \\ 6 & 0 & 0 & 0 & 0 & 0\end{array}$

Aseptic meningitis includes non-paralytic poliomyelitis and aseptic meningitis. Other diseases includes diseases other than poliomyelitis and aseptic meningitis.

$\mathrm{P} 1=$ poliomyelitis Type $1 ; \mathrm{P} 2=$ poliomyelitis Type $2 ; \mathrm{P} 3=$ poliomyelitis $\mathrm{Typ} \theta 3 ; \mathrm{E}=\mathrm{ECHO}$ virus Туре 6.

* In four cases an ECHO virus was also recovered from faeces.

** In three cases an ECHO virus was also recovered from faeces.

The data presented show statistically significant differences between the number of ECHO strains encountered in the aseptic meningitis group and the number found in the group of other diseases. The difference is even more striking when the poliomyelitis and the aseptic meningitis groups are compared where the evidence in favour of an aetiological relationship between ECHO virus Type 6 and aseptic meningitis is strong.

More significant, perhaps, is the successful isolation of ECHO virus Type 6 from the cerebrospinal fluid of patients; six of these strains were recovered from twentyone fluids of patients with aseptic meningitis. There were nine fluids available from cases where faecal cultures had yielded virus and of these four contained the same Type of ECHO virus. Only two of the remaining twelve fluids were found to contain virus and one of the two patients concerned was shown to have an antibody rise to ECHO Type 6.

With regard to cultures of throat-washings there were four positive isolations, three of the patients concerned had virus in their stools. In the remaining case the isolation of the ECHO virus from the cultures of the throat-washings was the only indication of an infection with this agent. 


\section{Serological findings}

Neutralization tests were carried out on paired sera taken from twelve poliomyelitis virus excretors and fifteen cases from whom ECHO virus had been isolated. The poliomyelitis sera were included as a control on the specificity of the tests. With regard to the ECHO sera the first blood sample, as a rule, was drawn within

Table 2. Neutralizing antibody titres against ECHO virus Type 6 in patients with aseptic meningitis and poliomyelitis

\begin{tabular}{|c|c|c|c|c|c|}
\hline Patient & Diagnosis & $\begin{array}{c}\text { Virus } \\
\text { isolated }\end{array}$ & $\begin{array}{c}\text { Interval } \\
\text { onset of } \\
\text { disease-first } \\
\text { bleeding } \\
\text { (days) }\end{array}$ & Serum 1 & Serum 2 \\
\hline E.H. & Aseptic m. & Echo & 9 & $64 *$ & 128 \\
\hline M.E. & Aseptic m. & Echo & 3 & 4 & 128 \\
\hline U.I. & Aseptic m. & Echo & 16 & 64 & 64 \\
\hline A.B. & Aseptic m. & Echo & 6 & 32 & 32 \\
\hline K.E. & Aseptic m. & Echo & 5 & 4 & 512 \\
\hline E.F. & Aseptic m. & Echo & 4 & 128 & 512 \\
\hline Т.H. & Aseptic m. & Echo & 4 & 4 & 128 \\
\hline H.B. & Aseptic m. & Echo & 3 & 128 & 128 \\
\hline B.B. & Aseptic m. & Echo & 4 & 128 & 512 \\
\hline K.T. & Aseptic m. & Echo & 1 & $<2$ & 256 \\
\hline s.s. & Aseptic m. & Echo & 3 & $<2$ & 512 \\
\hline E.S. & Aseptic m. & Echo & 9 & 16 & 256 \\
\hline M.K. & Aseptic m. & Echo & 5 & $<2$ & 32 \\
\hline R.G. & Aseptic m. & Echo & - & 128 & 128 \\
\hline E.H. & Aseptic m. & Echo & - & $<2$ & 128 \\
\hline H.E. & Poliomyelitis & Polio 1 & - & 64 & 32 \\
\hline K.N. & Poliomyelitis & Polio 1 & 12 & 2 & 16 \\
\hline G.W. & Poliomyelitis & Polio 2 & - & $<2$ & 2 \\
\hline G.H. & Poliomyelitis & Polio 3 & - & $<2$ & $<2$ \\
\hline G.W. & Poliomyelitis & Polio 3 & - & 2 & 2 \\
\hline N.M. & Poliomyelitis & Polio 3 & 19 & $<2$ & $<2$ \\
\hline L.L. & Poliomyelitis & Polio 3 & - & $<2$ & $<2$ \\
\hline J.R. & Poliomyelitis & Polio 3 & - & 64 & 64 \\
\hline A.A. & Poliomyelitis & Polio 3 & - & $<2$ & $<2$ \\
\hline P.U. & Poliomyelitis & Polio 3 & 7 & $<2$ & 2 \\
\hline A.D. & Poliomyelitis & Polio 3 & 10 & $<2$ & $<2$ \\
\hline M.M. & Poliomyelitis & Polio 3 & 7 & $<2$ & $<2$ \\
\hline
\end{tabular}

* Reciprocal of $50 \%$ neutralizing end-point against $100 \mathrm{ID}_{50}$ of ECHO virus Type 6 .

a week of onset of the disease while the first blood sample from poliomyelitis patients was collected somewhat later in the course of the disease. The second blood sample was collected 14 or more days after the first bleeding. The results of the neutralization tests are shown in Table 2 and may be summarized as follows: ECHO-sera obtained within 5 days of onset of the aseptic meningitis usually had a low antibody level, but a rise in type-specific antibody was demonstrated in the second specimen. Thus, in nine out of ten paired sera an antibody rise was observed. In one instance, with a substantial antibody level in the first serum, no change of 
titre was noted. On the other hand, three out of four paired sera, with the first serum collected later than 5 days after onset, a high antibody titre was observed in the first specimen and no subsequent rise in antibody was demonstrated.

Nine out of twelve paired sera from poliomyelitis cases showed no antibodies or only traces of antibody against ECHO virus Type 6, while two paired sera had a high level of antibody to ECHO virus in both specimens. Unfortunately the onset of the poliomyelitis disease was not recorded for these two cases. In one instance a small increase in antibody titre was observed but this rise occurred rather late in the course of the disease.

\section{Clinical and epidemiological observations}

Clinical observations. Paralytic poliomyelitis is defined clinically as an acute febrile illness with signs of central nervous system involvement and demonstrable loss of muscular power due to paralysis. Aseptic meningitis is an acute febrile illness with signs of central nervous system involvement but no paralysis.

The syndrome, aseptic meningitis, has a diverse etiology, and only laboratory examination can lead to a differential diagnosis. This report is primarily concerned with the relationship between ECHO virus Type 6 and aseptic meningitis and the signs and symptoms recorded below are those observed in patients from whom the virus had been isolated. Although the ECHO viruses have been isolated from normal individuals on a number of occasions Type 6 has been found in such persons much less commonly than other ECHO antigenic Types. Thus Davis \& Melnick (1956) report that Type 6 was only encountered once in 212 enteric virus isolations during a long-term study of healthy children. The cases presented here may be regarded as forming a selected group inasmuch as the patients were hospitalized and were presumably more severely ill than might be expected in a true crosssection. It should also be mentioned that the hospital records did not always give full clinical details so that a number of cases of aseptic meningitis may have been missed and the figures of incidence must be taken as minimal.

The onset was, as a rule, abrupt with a rapid rise of temperature to a high level for a few days falling to normal within a week.

Headache was recorded in all cases except in two children where a case history was difficult or impossible to obtain due to the children's age and their condition at the time of admission to the hospital. The headache started at the onset of the disease, and could be most painful.

Nausea or vomiting was recorded in twenty-six out of forty-seven cases.

Muscle pain occurred frequently. Thus, out of forty-seven cases twenty-six complained of pains or stiffness in the back, ten had abdominal pains and four had pains in the extremities. The nature of the pains was not analysed in detail.

Pleurodynia was recorded in eleven out of forty-seven cases.

Fever. All cases had fever, i.e. above $37 \cdot 5^{\circ} \mathrm{C}$. Twenty-three out of forty-seven patients had a maximum temperature $\geqq 39 \cdot 0^{\circ} \mathrm{C}$. The fever lasted for approximately 1 week, though, in some cases the period was extended. Recurrence of fever was not recorded perhaps due to difficulties in obtaining exact information on this symptom. 
Stiffness of the neck was noted in forty-one cases.

Convulsions at the onset of the disease was observed in two children.

No definite paralysis was recorded in any of the patients from whom ECHO virus Type 6 was recovered.

Cerebrospinal fluid. Lumbar puncture was performed in all cases, and an increased number of leucocytes was always observed. The number of cells ranged from a few cells to 541 cells per cu.mm. with about 75 cells as the mean. The lumbar puncture usually was performed within 1-3 days of admission to the hospital. In the few cases where serial punctures were carried out the leucocytes were predominantly polynuclear at the onset of the disease while mononuclear cells dominated later on. It should be pointed out that the number of cells showed great variation where multiple punctures were performed, and a priori one might expect that in some cases one or more out of several punctures would show a normal cell count.

It was mentioned under virus isolations that $\mathrm{ECHO}$ virus was recovered from two patients with a diagnosis other than poliomyelitis and aseptic meningitis. In both instances one single spinal fluid cell count was undertaken, and the number of cells found to be within the normal range. In the one case, fever, stiffness of back, and pleurodynia were observed, but there was no stiffness of the neck. The diagnosis was pleurodynia. The second case had headache, vomiting, stiffness of back and neck and a sore throat. This patient was discharged with a diagnosis of febrile catarrh.

\section{Epidemiological observations}

Fifty-eight strains of ECHO virus Type 6 were recovered from ninety-eight patients with a diagnosis of non-paralytic poliomyelitis or aseptic meningitis; in a few cases virus was isolated from more than one source so that altogether fiftyone patients yielded ECHO virus upon laboratory examination. From the same

Table 3. Isolation of poliomyelitis and ECHO viruses from stools obtained from 313 cases admitted to hospitals in the southern part of Norway

\begin{tabular}{|c|c|c|c|c|c|c|c|c|c|c|c|c|}
\hline \multirow[b]{2}{*}{ Year } & \multicolumn{6}{|c|}{ Paralytic poliomyelitis } & \multicolumn{6}{|c|}{ Aseptic meningitis } \\
\hline & $\begin{array}{l}\text { No. } \\
\text { tested }\end{array}$ & $\begin{array}{c}\text { No. } \\
\text { positive }\end{array}$ & $\mathbf{P} 1$ & $\mathbf{P} 2$ & P 3 & $\mathbf{E}$ & $\begin{array}{c}\text { No. } \\
\text { tested }\end{array}$ & $\begin{array}{c}\text { No. } \\
\text { positive }\end{array}$ & P 1 & P2 & P 3 & $\mathrm{E}$ \\
\hline 1952 & 22 & 19 & 19 & 0 & 0 & 0 & 14 & 6 & 6 & 0 & 0 & 0 \\
\hline 1953 & 59 & 36 & 3 & 0 & 32 & $1 *$ & 35 & 22 & 4 & 1 & 13 & $4^{*}$ \\
\hline 1954 & 22 & 11 & 7 & 0 & 4 & 0 & 26 & 10 & 6 & 0 & 4 & 0 \\
\hline 1955 & 37 & 22 & 13 & 3 & 6 & 0 & 98 & 60 & 6 & 1 & 5 & $48 * *$ \\
\hline
\end{tabular}

group of patients twelve poliomyelitis strains were isolated. In Table 3 are shown the results of the isolation experiments for 1955 compared with those obtained for 1952, 1953 and 1954. Only faecal samples have been considered in this table because these were the only ones examined in the years preceding 1955 . The findings 
for 1955 are at variance with those for 1952,1953 and 1954 . In 1952 only poliomyelitis strains Type 1 were found, but in 1953 five strains were encountered which could not be typed by means of specific poliomyelitis sera. Four of these strains were recovered from cases of aseptic meningitis. There is a highly significant difference, though, between the number of non-poliomyelitis strains recorded for 1953 and 1955 . In addition, in 1953 a great many poliomyelitis Type 3 strains were encountered. In 1954 again only poliomyelitis strains were isolated. Thus, the findings for 1955 deserve special attention. It should be emphasized that the isolations recorded in Table 3 were from material received from the same six hospitals throughout the period 1952 to 1955 , and the resulting figures should give a reliable picture of the changing incidence of enteric viruses throughout these years.

Cases of poliomyelitis are reported to health authorities in Norway, but aseptic meningitis is not notifiable. Consequently there is no reliable information regarding the incidence of aseptic meningitis (including non-paralytic poliomyelitis) for the country as a whole. However, the relative frequency of these illnesses may be evaluated by the number of cases of each category admitted to the hospitals. Data have been obtained from five of the six above-mentioned hospitals, and the figures are as follows: In 1953316 cases of paralytic poliomyelitis and 122 cases of aseptic meningitis were recorded. In 1954123 paralytic cases and sixty-four cases of aseptic meningitis were reported, while in 1955 the number of paralytic cases was seventy-one in contrast to 137 patients with a diagnosis of aseptic meningitis. A statistical analysis of the data shows a highly significant difference between the figures found for 1955 and those found for 1954 or 1953. The epidemiological observations support the view that one had to deal with a different situation in 1955 to that in 1954 and 1953. It should be stressed that additional epidemiological investigations did not indicate that other known epidemic diseases occurred with higher frequency in 1955 than in the preceding years. Thus, there is every indication that the relatively high frequency of aseptic meningitis in 1955 was due to what is considered to be ECHO virus infections.

\section{DISCUSSION}

Although the association of ECHO virus Type 6 with aseptic meningitis has been reported by several workers, the evidence regarding its importance as a causative agent of the disease depends mainly on the work of Davis \& Melnick (1956) who demonstrated specific antibody response in sera from patients from whose stools the virus was isolated.

These findings are fully confirmed by the results recorded here, which show relatively large numbers of positive isolations from the stools of patients suffering from the disease with a high proportion of specific antibody responses in the sera of those patients examined. Further evidence in favour of accepting ECHO virus Type 6 as one of the causative agents of aseptic meningitis is provided by the isolation of the virus from the CSF of a number of patients, some of whom were also excreting the virus in their stools. In two of these cases a specific antibody response was demonstrated. It seems clear, therefore, that ECHO virus Type 6 can 
set up an inflammatory aseptic meningitis and that the infection results in a specific antibody response.

The relative infrequency of positive isolations from mouth and throat washings and the frequency of isolations from the stools of patients suggest that the concentration of the virus in the lower gut is probably greater than in the upper respiratory passages. Whether this is due to the multiplication of the virus in the gut is not clear, but in another study reported elsewhere (Lahelle, 1957), where one patient showed virus concentration of $10^{6} \mathrm{ID}_{50}$ per $\mathrm{g}$. of faeces, it does seem that this very high concentration was due to multiplication of the virus in the gut.

Owing to the fact that aseptic meningitis is not a notifiable disease in Norway accurate epidemiological information about this condition is not available. If, however, the records summarized in Table 3 are accepted as representing the incidence of paralytic poliomyelitis and aseptic meningitis in a cross-section of the population of Southern Norway then it seems reasonable to conclude that aseptic meningitis was much more common in 1955 than in the previous years and that this changing pattern was due to the appearance of ECHO virus infections, which previously had not been evident.

\section{SUMMARY}

1. An investigation of ninety-eight cases of aseptic meningitis admitted to hospital resulted in the isolation of ECHO virus Type 6 from fifty-one patients.

2. The viruses were cultivated in both human embryonic skin-muscle tissue and human amniotic cell tissue. The latter was found to be more satisfactory.

3. Forty-eight strains were isolated from the stools of patients, six from the cerebrospinal fluid and four from throat-washings.

4. Serological examination of patients from whom the virus was isolated showed that a significant proportion of patients exhibited a specific antibody response. This included three out of six patients with the virus in their cerebrospinal fluid.

5. The clinical picture of aseptic meningitis from which cases ECHO virus was isolated cannot be distinguished from that caused by other known viruses.

6. The evidence presented supports the claim that ECHO virus Type 6 is one of the causes of aseptic meningitis.

Grateful appreciation is acknowledged to Prof. P. M. Holst (Oslo), Prof. Johs. Böe (Bergen), Dr B. Helland-Hanssen (Molde), Dr O. Römcke (Drammen), Dr R. Tingstad (Namsos), and Dr A. H. Brinchmann (Bærum), for providing specimens and case records. I am also grateful to Mrs B. Zapffe and Mrs L. Kohmann for expert technical assistance.

\section{REFERENCES}

Committee on the ECHO VIRUSEs (1955). Science, 122, 1187.

Davies, D. C. \& Melnick, J. L. (1956). Proc. Soc. exp. Biol., N.Y. 92, 839.

Duncan, D., Silverthorne, N., MoNaughton, G. A., Johnsson, C. C. R. \& Rhodes, A. J. (1954). Canad. J. publ. Hlth, 45, 55.

Evaluation of 1954 Field Trial of Poliomyelitis Vaccine. Summary Report. Vaccine Evaluation Center, University of Michigan, Ann Arbor, Michigan, 12 April 1955. 
Honig, E. I., Melnick, J. L., Isacson, P., Parr, R., Myers, I. L. \& Walton, M. (1956). J. exp. Med. 103, 247.

LAHELLE, O. (1954). Acta path. microbiol. scand. 35, 119.

LaHElle, O. (1956). Acta path. microbiol. scand. 39, 338.

LAHELle, O. (1957a). Nord. med. 57, 424.

LAHELLE, O. (1957b) - Acta path. microbiol. scand. 40, 436.

Melnick, J. L. (1954). Amer. J. publ. Hlth, 44, 571.

Ramos-Alvarez, M. \& Sabin, A. B. (1954). Proc. Soc. exp. Biol., N.Y. 87, 655.

Riordan, J. T., Ledinko, N. \& Melnick, J. L. (1952). Amer. J. Hyg. 55, 339.

Robbins, F. C., Enders, J. F., Weller, T. H. \& Florentino, G. L. (1951). Amer. J. Hyg. $54,286$.

Svedmyr, A., Merén, B. \& KJellén, L. (1956). Acta med. scand. 154, Suppl. $316,20$.

(MS. received for publication 4. П. 57) 